\title{
A study on use of miniature dielectric compound parabolic concentrator (dCPC) for
} daylighting control application

\author{
Xu Yu ${ }^{l}$, Yuehong Su${ }^{l} *$, Hongfei Zheng ${ }^{1,2}$, Saffa Riffat ${ }^{l}$ \\ ${ }^{1}$ Institute of Sustainable Energy Technology, Department of Architecture and Built Environment, University \\ of Nottingham, University Park, NG7 2RD, UK \\ ${ }^{2}$ School of Mechanical Engineering, Beijing Institute of Technology, Beijing 100081, China \\ * Corresponding author. Tel.: +44 115 8467872; fax: +44 1159513159. \\ E-mail address: yuehong.su@nottingham.ac.uk
}

\begin{abstract}
Low-concentration solid dielectric compound parabolic concentrator ( $\mathrm{dCPC}$ ) and its variations have been widely regarded as an attractive solution to reduce the cost of a photovoltaic (PV) system, particularly for building-integrated application. Different from a mirror CPC, a dCPC allows the light beyond its acceptance angle to penetrate through its lateral surface. This escaped light could be actually used for daylighting, so the dCPC offers a potential for combined PV and daylighting application suitable for the atrium buildings or large green houses. In the modern buildings, an advanced daylighting system such as prismatic panels is used to balance between harvesting daylight and preventing excessive solar heat gain. In contrast, this study aims to evaluate the advantage of the miniature solid $\mathrm{dCPC}$ over common prismatic structures according to their daylight transmittance values under both standard and real sky conditions. A commercial optical analysis software PHOTOPIA is firstly used to compare the daylighting control performance between a dCPC rod and two common prismatic elements. The effect of solar altitude and azimuth angles changing with time is considered. A preliminary test under a solar simulator and a real sky condition is also introduced to provide experimental evidence regarding the advantageous feature of a dCPC rod for daylighting control.
\end{abstract}

Keywords: daylighting control, dielectric parabolic compound concentrator (dCPC), prismatic, transmittance, illuminance, Photopia simulation, experimental measurement

\section{Introduction}

\subsection{Daylighting in buildings}

In buildings, especially commercial office buildings, air-conditioning and artificial lighting system are widely used to create a thermally and visually comfortable built environment, and these systems are responsible for most of the energy consumption [1]. In the worldwide background of depletion of fossil fuels, reducing the energy consumption from building has been urgent. Recently, sufficient use of daylighting is popular in architecture design as an alternative to electrical lighting. Additionally, daylighting is also a light source whose colour rendering most closely matches human visual response. Windows are the traditional daylighting design, but it is also regarded as the weakness of the building envelope in reducing the building energy consumption [2]. The main drawbacks include increased cooling load caused by excessive solar heat gain 
through window; and visual discomfort due to non-uniform light distribution within interior space. All the above drawbacks may cause the occupants being reluctant in efficient use of daylighting and then switch to artificial lighting instead. As a result, the potential energy saving from daylighting may diminish. Therefore,

4 Lim concluded that an energy sufficient and visual comfortable daylighting solution should balance among the harvesting of natural light, prevention of heat gains and control of discomfort glare [3].

In the past decades, development of innovative daylighting systems has been addressing these issues. The most important purpose of innovation daylighting system is to reduce associated problems like heat gain, excessive light level and glare [4]. Light re-directing elements such as lightshelf and dynamic louvers may be combined with the windows to extend daylight benefit area by a couple of metres and reduce the high levels of daylight near the window [5]. The daylight guiding systems such as lightpipes and optical fibres are the emerging technology to bring daylight to the deep interior of a building where daylight through a conventional window can hardly reach. Roof-installed vertical lightpipes have been successfully commercialised and accepted in the past decades [6]. Meanwhile, for wall-mounted horizontal daylighting guiding applications, a so-called anidolic daylighting system is trying to penetrate into market. This system provides more homogenized daylight distribution by increasing the illuminance level at rear part of the room while reduce the illuminance level near windows and compared to light shelf, it is able to catch more skylight from the sky hemisphere due to the shape of its collector [7]. However, requirement of high tracking accuracy has caused extremely high price for sunlight concentration and optical fibre guiding systems, this has been a big barrier for such systems to enter the market $[8,9]$

Atrium represents a modern architectural structure to introduce daylighting; it can provide bright and comfort nature light in the core of the building. The internal illuminance of 1000-2000lux is required for atrium design [10]. However, thermal stratification is a significant problem in the tall atriums. Diffusing glazing or shading under atrium roofs are often used to mitigate the overheating problem. Incorporation of semi-transparent photovoltaic (PV) modules with the atrium (or green house) roofs has been in practice in the recent years. Shading by PV glazing needs less maintenance and economically advantageous due to electricity generation compared with other common shading methods and the user perception of PV atrium roofs were also quite positive [11]. On the other hand, in the recent years, the development of advanced optical elements made it possible to selectively redirect daylight into building areas within certain acceptance angle [12], they can be designed sensitively to the sun elevation angle to reflect away most of direct sunlight at higher solar altitude while allow the diffuse skylight or low altitude sunlight to transmit for daylighting and heat [13].

\subsection{Dielectric compound parabolic concentrator (dCPC)}

33 The Compound Parabolic Concentrator (CPC) is a well-known non-imaging low concentration solar concentrator. It was proposed by Roland Winston and further developed by Walter Welford in the 1970's [14, 15] and since then, lots of literatures have been published on investigation of its application for PV and solar 
1 thermal systems [16]. Generally, CPC is regarded as sufficient solution to the high cost of PV system by 2 reducing the area of solar cell; and it also has the advantage of eliminating the requirement of solar tracking 3 system due to its wide angular acceptance range. The dielectric compound parabolic concentrator (dCPC) is 4 an alternative to the conventional mirror CPC [17]. The dielectric material is molded within the profile of

5 CPC. Rather than using the high reflective materials for the lateral wall of CPC, it relies on total internal reflection at the air-dielectric interface to achieve almost perfect mirror reflection, so that the maximum solar radiation within the acceptance angle can reach the base of dCPC. Moreover, due to the air-dielectric interface at the entrance aperture and Snell's Law of refraction, the dCPC has an additional advantage over the mirror CPC of the same profile, i.e. wider acceptance angle. Therefore, the application of dCPC for the photovoltaic systems has been widely studied, especially for building-integrated PV systems [17-19]

However, there is another optical property of $\mathrm{dCPC}$, which is rarely investigated by researchers: when the incidence angle of light is beyond the acceptance angle, there will be some light escaping from the lateral wall of a solid $\mathrm{dCPC}$, it would be attractive if this escaped light can be used as daylighting in buildings and the $\mathrm{dCPC}$ can therefore be a potential advanced daylighting control element to transmit the solar light selectively like prismatic panel. Walze et al [20] have studied use of micro dielectric CPC structure for light-guiding and sun-shading system with facet-selective coating and indicated that it is most suitable for applications on roof windows. Use of a dCPC panel with combined PV and daylighting control features has therefore inspired the study presented here.

As mentioned before, the application of dCPC on the building-integrated PV system has been well evaluated. Thus this paper will mainly focus on the comprehensive investigation of $\mathrm{dCPC}$ as an advanced daylighting control system. At first, the main working principle of dCPC will be introduced briefly. Then the commercial ray-tracing simulation software PHOTOPIA was used to simulate the ray-path within $\mathrm{dCPC}$ for various incidence angles. At the same time, measurements under both solar simulator and real sky condition were taken. In this paper, the optical transmittance is quoted to represent the daylighting control performance by $\mathrm{dCPC}$, which is regarded as the basic parameter to evaluate the optical transmission performance of a daylighting system [21].

\section{Optical principle of a dielectric CPC}

Before introducing the optical principle of $\mathrm{dCPC}$, it should be initially noted that for the light travelling from material with high refraction index to the low refraction index material, the light can pass through the interface only if the incidence angle is smaller than the critical incidence angle, which is defined by: 
where $\theta$ is the critical incidence angle; $n_{2}$ is the lower refraction index; $n_{1}$ is the higher refraction index. For example, an acrylic-air interface $\left(n_{2}=1 ; n_{1}=1.5\right)$ has a critical incidence angle of about $41.8^{\circ}$ $\left(\sin ^{-1}(1 / 1.5)\right)$, larger than which light will undergo total internal reflection in acrylic.

4 Figure 1 illustrates three representative ray paths within a dCPC and this is summarised in Table 1. These three ray paths may explain the fundamental principle of a dCPC for potential combination of Daylighting and PV application.

However, a dCPC has a disadvantage of high dielectric material usage and therefore induced heavier weight than a mirror CPC. Truncation is a practical and cost effective solution to mitigate this issue for dCPC [22]. Normally, a CPC can be truncated by $1 / 3$ to $1 / 2$ of its full height from the top. Although it will be penalized by the reduction of the geometric concentration ratio, it can in return increase the acceptance angle slightly and substantially reduce the fabrication material usage [23]. For instance, as shown in Figure 2, a CPC with a geometric concentration ratio of $4(20 \mathrm{~mm} / 5 \mathrm{~mm})$ and height of $48.4 \mathrm{~mm}$ is truncated from the top by $50 \%$, a truncated CPC with geometric concentration ratio of $3.6(18 \mathrm{~mm} / 5 \mathrm{~m})$ is formed. It can be observed that more than $50 \%$ of the material usage is saved with the loss in geometric concentration ratio by only $10 \%$. Therefore, the daylighting control performance of a truncated $96 \mathrm{~mm}$ long miniature $\mathrm{dCPC}$ rod with the base width of $5 \mathrm{~mm}$, entry aperture width of $18 \mathrm{~mm}$ and height of $24.2 \mathrm{~mm}$ (dCPC-3.6), will be investigated in the following sections. According to the feature of dCPC, the inner and outer acceptance angle of this Dcpc is $14.5^{\circ}$ and $22.05^{\circ}$, respectively.

\section{Methodology}

\section{$21 \quad 3.1$ Optical simulation}

Ray-tracing simulation has been widely accepted to predict the performance of daylighting system in building application [4]. The commercial optical analysis software PHOTOPIA provides a fast and accurate forward ray-tracing photometric analysis. As it can cope with high number of reflections and refractions that occur within systems, it is able to undergo comprehensive performance evaluation for non-imaging optical design, and the difference between the prediction and measured value of an optical efficiency can be within $1 \%$ or $2 \%$ [24]. Another advantage of PHOTOPIA is that it is 3D CAD based simulation software which is capable of importing CAD object files; the optical properties of the imported objects can be defined as reflective, transmissive or refractive. Then the material can be assigned, which is provided in a large library of commercially available lamps and materials. The PHOTOPIA is also capable of simulating daylighting or solar energy collection systems, it uses the IESNA PR-21 daylight equations to model daylighting input into devices such as light pipe or solar collector under various sky conditions and solar positions [25].

When the PHOTOPIA deals with the lens, the reflection and refraction coefficient at air-dielectric interface is determined by Fresnel's equation while the refraction angle is calculated by Snell's law. It will also consider 
1 the optical absorption in the dielectric material when the light passes through the material on the basis of

2 Beer's Law, which can be written by [16]:

$3 \quad \eta=e^{-\alpha L}$

4 where $\alpha$ is the extinction coefficient, with the unit of $\mathrm{m}^{-1}, \boldsymbol{L}$ is the optical path, with the unit of $\mathrm{m}, \boldsymbol{\eta}$ is the 5 transmissivity of the material.

6 The material used for dCPC rod is acrylic, whose transmittance is measured as 0.9 for the thickness of $8 \mathrm{~mm}$. 7 The refraction index is assumed to be 1.5, which is a commonly accepted value for standard acrylic. 8 According to the Fresnel Reflection Loss Equation [26], for the normal incidence angle at the air-acrylic 9 interface, the Fresnel Power Reflection Coefficient is expressed as:

$$
R_{f}=\frac{\left(n_{1}-n_{2}\right)^{2}}{\left(n_{1}+n_{2}\right)^{2}}
$$

11 Where $\boldsymbol{n}_{1}$ is the refraction index of acrylic, which is $1.5, \boldsymbol{n}_{2}$ is the refraction index of air, which is 1 . The $R_{f}$ can be calculated to be $4 \%$. Considering the loss on both sides of acrylic sheet, the transmissivity of the acrylic is $98 \%$. According to Equation 2, the extinction coefficient $\boldsymbol{\alpha}$ for the acrylic we used is $2.525 \mathrm{~m}^{-1}$, as the PHOTOPIA uses inch instead of meter as default unit, therefore the extinction coefficient $\alpha$ is 0.0641 inch 1. This data can be edited in the file for the standard acrylic. It is worth to mention that the effect of wavelength on the refractive index and extinction coefficient was neglected.

\section{Ray-tracing simulation}

18 In order to verify the optical principle of dCPC, two dCPC-3.6s with different treatments on their basis were modelled and imported to the PHOTOPIA. One dCPC without coating on its base was considered for daylighting application only, which is names as non-coated $\mathrm{dCPC}$, while the base of the other dCPC was assumed to have a black coating, which may stand for a PV cell in real application, and it may be named as base-coated dCPC. Meanwhile, another two common prismatic elements (with shape of equilateral triangle and isosceles right triangle) were also simulated for comparison. Figure 3 shows the cross-section of four studied structures, with the width of their entry apertures being kept the same so that the amount of light entering these three prisms was the same. It should be mentioned that the ray-tracing simulation is for the purpose of acknowledging the ray paths within four prismatic structures under various incidence angles, only the ray-tracing on the cross-section plan was given here. The ray-tracing simulation on the three-dimensional (3D) aspect (skew rays on front aperture) is presented in daylighting analysis. 


\section{$1 \quad$ Daylighting simulation}

2 Under real sky condition, due to the changing azimuth and altitude of the sun, and also the hemisphere sky

3 dome, the skew rays entering the stationary prismatic elements are much more representative than the rays

4 parallel to the cross-sectional plan. Therefore, a three dimensional (3D) simulation is more relevant to the

5 actual application. The Daylighting Simulation Function in PHOTOPIA provides the convenience to do such

6 simulation; it includes sun and sky dome as "lamp" for use in modelling the daylighting collection device

7 based on the IESNA RP-21 daylight equation. The position of the sun (solar disk) and its lumen output can be

8 adjusted to model the sun under various solar altitudes and azimuths. To further investigate the daylighting

9 control function for the dCPC rod with or without coating on its base and other two common prisms,

10 simulation was conducted under PHOTOPIA sun and sky dome for two selected typical sunny days, summer

11 and winter solstices. As the simulation location was chosen to be Nottingham, UK $\left(53^{\circ} \mathrm{N}, 1.2^{\circ} \mathrm{W}\right)$, all the four

12 optical elements were assumed to align with their long axes in the east-west direction and be tilted 30 degree

13 to the south, as illustrated in Figure 4. In the real application, during the the cooling season (March to

14 September), the direct sunlight needs to be absorbed by the base of dCPC to achieve shading effect, during

15 which period the solar zenith angle at noon various from $30^{\circ}$ to $54^{\circ}$ in Nottingham; given that the outer half

16 acceptance angle of the studied dCPC is about $22.05^{\circ}$, the dCPC should be titled about $30^{\circ}$ to fit in the angular

17 range required. In this case, the direct sunlight can still be transmitted during the heating season (September to 18 March)

\section{$20 \quad 3.2$ Experiment under solar simulator and real sky}

\section{$21 \quad$ Experiment setup}

22 Following the 2D and 3D ray-tracing simulation, preliminary experiments under solar simulator and real sky condition were conducted to measure the transmittance of $\mathrm{dCPC}$ rods. The main purpose of these experiments

24 is to verify the simulation results. The experimental system consists of three parts: dCPC rods, integrating box 25 and illuminance meters.

\section{1) $\quad$ dCPC rod}

27 The dimension of the manufactured $\mathrm{dCPC}$ rod is as same as ones modelled in ray-tracing simulation. It was made of normal acrylic material with refraction index of 1.5 and transmittance of $90 \%$ (measured for $8 \mathrm{~mm}$ thickness). The length of the dCPC rod is $96 \mathrm{~mm}$, see Figure 5. Additionally, for the purpose of comparison, one dCPC rod was affixed with a non-reflective material on its base, which represents the base-coated dCPC rod in simulation.

\section{2) Illuminance sensor}

33 The illuminance sensors were used to collect the experimental data. Six Skye Instrument SKL310 illuminance 34 sensors with the uncertainty of $\pm 3 \%$, were connected to Skye Instrument Datahog 2 data logger and 
1 simultaneously recorded the illuminance level. All these six illuminance sensors were pre-calibrated before

2 the experiments to make sure all the data were in the same level of accuracy.

3 3) Integrating box

4 The transmittance measurement was based on use of a photometric integrating box. The photometric 5 integrating box is an approximate and convenient approach to measure the transmittance, and it is easy to be 6 constructed. This approach has been proposed by the UK Building Research Establishment [24]. Figure 6

7 illustrates the configuration and picture of the photometric integrating box. The photometric integrating box is 8 a cubic box with its internal surface painted matt white so that light can be diffusely reflected to the internal 9 sensor. On the cover of the box, there is an aperture to admit the light into the box, the size of the aperture is 10 determined by the dimension of the measured objective. For the measurement of dCPC rod in this experiment, 11 it should be as same as the size of the entry aperture of dCPC rod. An internal illuminance sensor is attached 12 to the top panel and points downward; the reason for pointing downwards is that it can avoid direct light and 13 measure the reflected light only. Meanwhile another external sensor is placed upward near the aperture to 14 measure the outside illuminance, which stands for the amount of light penetrating through the aperture.

15 The theory and procedure of measuring the transmittance can be concluded as follows: firstly, as the geometry 16 and interior surface properties remains the same, there should be some certain relationship between the 17 illuminance level at the internal sensor point and the lumen entering the box opening. Therefore, a concept of conversion factor may be defined, which is expressed by Equation 4

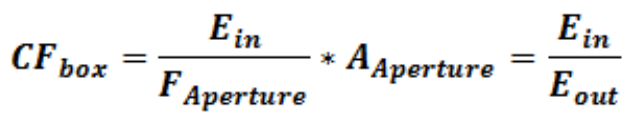

20 in which $\boldsymbol{C F}_{\boldsymbol{b o x}}$ is the conversion factor of the integrating box; $\boldsymbol{E}_{\boldsymbol{i n}}$ is the illuminance at the internal sensor 21 point when the aperture is void; $\boldsymbol{F}_{\text {Aperture }}$ is the lumen entering the box through the aperture; $\boldsymbol{A}_{\text {Aperture }}$ is the area of aperture; $\boldsymbol{E}_{\text {out }}$ is the external horizontal global illuminance. Joel Callow found that the conversion factor was approximately constant for a fixed box geometry and surface reflectance regardless of sky condition [25]. It can be determined through the calibration of an integrator box by simultaneously measuring the illuminance values.

When a dCPC rod is installed at the aperture, its transmittance can be obtained from the measured illuminance values and conversion factor, as below:

$$
T=\frac{F_{\text {Transmitted }}}{F_{\text {incidence }}}=\frac{E_{\text {in.CPC }} * A_{\text {Aperture }} / C F_{\text {box }}}{E_{\text {out.CPC }} * A_{\text {Aperture }}}=\frac{E_{\text {in.CPC }}}{E_{\text {out. } . C P C}} * \frac{1}{C F_{\text {box }}}
$$


1 Where $\boldsymbol{E}_{\text {in.CPC }}$ and $\boldsymbol{E}_{\text {out.CPC }}$ are the internal and external illuminance at measuring points when the aperture is

2 installed with dCPC rod, the transmittance can be simply given by dividing the internal-external illuminance

3 ratio measured with $\mathrm{dCPC}$ by the conversion factor of the integrating box.

5 In this experiment, a cubic integrating box with interior dimension of $300 * 300 * 300 \mathrm{~mm}^{3}$ was constructed, the side walls and the bottom board were made of $10 \mathrm{~mm}$ plywood to ensure the sturdiness of the box. However, the thickness of cover board should be considered carefully. Since the dimension of the aperture on the cover board was determined by the front aperture of dCPC rod $\left(18 \mathrm{~mm}^{*} 96 \mathrm{~mm}\right)$, if the thickness of cover board is too large, it might block some portion of light, especially at large incidence angles; while this blocked light can be redirected into the box if the aperture is installed with $\mathrm{dCPC}$ rod. As a result, the accuracy of the measurement would be influenced. Figure 7 illustrates the percentage of light loss due to different board thickness under various incidence angles, it is clear that there seem to be more light loss at higher incidence angle and thickness, the thinner board seems to be preferred, meanwhile, the strength of the board needs to be strong enough to hold the $\mathrm{dCPC}$ rod. Therefore, a steel plate with thickness of $0.8 \mathrm{~mm}$ was selected.

Before the experiment, a calibration work for the integrating box used was also taken and the results was shown in Figure 8, the results shows a good agreement Joel's conclusion that there is a constant value for a box with fixed aperture size and internal reflectance

Experiment under solar simulator

The transmittance for different incidence angles was measured under a solar simulator. The solar simulator is a device that provides illumination approximating natural sunlight. The solar simulator seems to be an ideal light source to provide stable light under laboratory conditions and its incidence angle to an object can be easily adjusted with rotation. The experiment was undertaken in the dark environment to ensure that the solar simulator was the only light source. During the measurement, the integrating box was placed under the solar simulator and tilted continuously from 0deg to $60 \mathrm{deg}$ to horizon. As the light from solar simulator was regarded perpendicular to the horizon. The tilted angle was taken as the incidence angle on the top of the integrating box. The procedure was as same as indicated before; the transmittance of dCPC rod with and without coating on its base was measured from incidence angle between 0-60deg with an interval of $5 \mathrm{deg}$.

\section{$28 \quad$ Experiment under real sky}

29 The outdoor experiments were conducted in Nottingham, UK $\left(52.58^{\circ} \mathrm{N}, 1.1^{\circ} \mathrm{W}\right)$ to compare the daylighting control features between non-coated $\mathrm{dCPC}$, base-coated $\mathrm{dCPC}$ and isosceles right triangle prism rods under both sunny and overcast weather conditions. These three optical rods were positioned with their longitudinal axis in the east-west direction and their front apertures tilted 30 degree, which is the same as daylighting simulation in Photopia. As shown in Figure 9, the experiment was taken on an open area so that shading effects from surroundings can be avoided. Three photometric integrating boxes were used and calibrated in order to determine their conversion factors under a real sky condition. The slot apertures of the boxes were 
1 fitted with the isosceles right triangle prism, non-coated $\mathrm{dCPC}$ and base-coated $\mathrm{dCPC}$. The transmittance

2 values of these optical rods were determined by substituting the monitored internal and external illuminance

3 values into Equation 5. One ideal sunny day $\left(9^{\text {th }} \mathrm{July}, 2013\right)$ and one ideal overcast day $\left(10^{\text {th }} \mathrm{July}, 2013\right)$ were

4 selected to undertake the experiment, the data were recorded every 1min from 8am to 6pm (British Summer

5 Time).

\section{4. Results and discussion}

\section{$8 \quad 4.1$ Ray-tracing simulation}

9 Figure 10-12 illustrated the ray path on the cross-section of the studied prismatic structures for incidence angle of $0^{\circ}, 10^{\circ}$ and $25^{\circ}$, respectively. It can be observed that for the incidence angle of $0^{\circ}$, it is clear that light is completely shaded by the base-coated $\mathrm{dCPC}$ rod and isosceles right triangle prism, and it transmits completely through equilateral triangle prism and partly through the non-coated $\mathrm{dCPC}$ rod. When the incidence angle increases to $10^{\circ}$, light can still be completely shaded by the base-coated dCPC rod; while it can partially transmit through the isosceles right triangle prism. When the incidence angle increases to $25^{\circ}$ which is larger than the outer half acceptance angle of the dCPC, part of the light can transmit through the base-coated dCPC from the lower side of its lateral wall, and the rest will be reflected by the assumed coating on its base, as shown with dotted lines. The ray-tracing results can verify the theoretical analysis of optical principle in Section 2.

The transmittance was adopted to represent the daylighting control effect of dCPC rod. Ray-tracing results were used to calculate the transmittance of the $\mathrm{dCPC}$ rods and prismatic structures, which is the ratio of the transmitted light to the incidence light on the entry of a rod. In PHOTOPIA simulation, the optical loss due to the reflection on the dielectric-air interface and absorption within the dielectric material were considered. Figure 13 shows the calculated transmittance values of dCPC rods and prismatic elements for different incidence angles. As indicated by the transmittance values, the base-coated dCPC rod can completely shade the light coming within its acceptance angle while the non-coated dCPC rod can only shade about 50\% of light. The equilateral triangle prism almost cannot shade and the isosceles right triangle prism can shade only for a small range of incidence angles.

\subsection{Experiment under a solar simulator}

The measuring results under the solar simulator and its comparison with the PHOTOPIA simulation results for the dCPC rods are shown in Figure 14. It can be observed that the measured results are higher than the simulated although their main trends are similar: most of the incident light is shaded for smaller incidence angle, but when the incidence angle is about $20-25^{\circ}$, there is a sudden increase in the transmittance for both coated and non-coated dCPC rods, and then most of the incident would penetrate beyond $25^{\circ}$. This trend agrees with the optical principle of dCPC. The difference between the measurement and the simulation may 
1 be mainly attributed to two factors: the geometry accuracy of the dCPC rods and the degree of parallelism of

2 light from the solar simulator. The sample dCPC rods were made using laser-cutting method, so it is difficult 3 to obtain a perfect parabolic profile. This therefore might affect the total internal reflection on the lateral wall 4 of the sample dCPC rods, and light might penetrate through the wall instead of total internal reflection. This can be evident from higher measured transmittance for small incidence angle. The effect caused by the degree of parallelism of light may be seen from the fact that the measured transmittance does not show a sharp change at the expected acceptance angle. This is because some of the rays from the solar simulator might deviate from the expected direction for an incidence angle setting.. In addition, the diffuse light reflected by surrounding objectives might also add to this effect. In order to minimize the influence of reflected light, the measurement was carried in the relatively dark environment, but the ideal environment seems to be hard to achieve. Other minor factors such as the thickness of the covering board, reading error of the illuminance sensor and the calibration between sensors can also cause small errors, but these factors have been minimized but seem to be unavoidable. Despite the difference between the simulation and measurement results, the main trend can still verify the optical characteristics of a dCPC rod and its advantage for daylighting control.

\subsection{Daylighting simulation}

The daylighting simulation results for summer and winter solstices are shown in Figure 15. The advantage in daylighting control by dCPC rod, especially base-coated $\mathrm{dCPC}$ rod over equilateral and isosceles right triangle prisms was clear on the summer solstice, i.e., most of the incident sunlight can transmit for daylighting in the morning and afternoon while more sunlight is rejected in the midday. While for the winter solstice, the sunlight is required for both illumination and solar heat gain, the dCPCs can still maintain relatively high transmittance to allow penetration of sunlight. These results revealed the seasonal daylighting control ability for dCPC rod as a daylighting element. Figure 16-17 further indicated the seasonal variance of transmittance and the corresponding daylighting level under sunny sky condition, respectively. The results show that under sunny sky condition in summer, the dCPC rods, base-coated dCPC rod in particular, can effectively reduce the transmittance and solar heat gain as well, but still guarantee the adequate indoor brightness if compared to the illuminance level required by atrium, and considerable cooling load could be reduced. And on sunny winter time, the high transmitted light could bring both daylight and beneficial heat gain to reducing the lighting and heating load within the building.

Moreover, transmittance under overcast sky condition for these four typical days was also simulated in PHOTOPIA. Since the diffused light dominates and there is no direct sunlight, there should be slight daily and seasonal variance of transmittance for each of the prismatic structure. The results from Figure 18 proved the above statement, which means, all these four prismatic structure will act as the conventional windows to have a fixed transmittance throughout the year under the overcast sky condition. It is worth to mention that under overcast sky, the transmittance for equilateral and isosceles right triangles are higher than both $\mathrm{dCPC}$ rods, but

Figure 19 indicated that the transmitted illuminance level is still acceptable for atrium. Therefore, according 
1 to the simulated seasonal daylighting results, for the comprehensive consideration of sunny and overcast sky

2 condition, compared to equilateral and isosceles right triangles, the dCPC rod, particularly the base-coated

$3 \mathrm{dCPC}$ rod is preferred as daylighting element due to its daylighting control ability.

\section{$4 \quad 4.4$ Experiment under real sky condition}

5 Figures 20-21 show the daily transmittance variation under a sunny and overcast sky, respectively; and the

6 variance of outdoor illuminance is also presented. It can be observed that, for both sunny and overcast sky 7 condition, the main tendency of the variation of transmittance throughout the day is clear and very similar to 8 the simulation results. Compared to the non-coated dCPC rod, the base-coated dCPC rod can largely reduce 9 the amount of daylight penetration when the sunlight intensity is high. Moreover, on sunny day, when the 10 direct sunlight dominates, it has a great potential for daylighting control throughout the day, it can offer 11 relatively higher transmittance in the morning and afternoon when the external illuminance is low, and lower 12 transmittance during the midday period, at which time there is unwanted direct sunlight and excessive heat 13 gain as well. This feature is unique when compared to the non-coated $\mathrm{dCPC}$ rod and the isosceles right 14 triangle prism, which do not have the ability to reduce the transmittance at the middle of day. Therefore, the 15 base-coated dCPC rod seems to have great potential for daylight control when the sunlight intensity is high. 16 Additionally, the light reached the base of the base-coated $\mathrm{dCPC}$ rod has higher intensity and this provides a potential for PV applications. Meanwhile, under overcast sky condition, in which diffused light dominates, all 18 these three structures could provide relatively constant transmittance throughout the day. The non-coated $19 \mathrm{dCPC}$ rod had the highest transmittance of about $80 \%, 55 \%$ for the isosceles right triangle prism; and the 20 based-coated $\mathrm{dCPC}$ rod had a transmittance of about $48 \%$, which is high enough to provide daylighting 21 illumination under overcast sky. In general, for comprehensive consideration of sunny and overcast sky condition, the base-coated dCPC rod has great potential for daylighting control: it can offer relatively higher transmittance when more daylighting is wanted and lower transmittance when daylight is excessive. On the other hand, it also provides an option to be combined with PV cell for electricity generation with its basic ability of light concentration.

\section{Conclusions}

This study has had a look into the potential of a solid dielectric compound parabolic concentrator (dCPC) as a daylighting control device, in addition to its suitability for building-integrated concentration PV application. This is based on the optical characteristics of a solid dCPC which allows the light beyond its acceptance angle to penetrate through its lateral surface. The light transmittance has been adopted as a performance indicator to denote the daylighting performance. The work conducted includes ray-tracing analysis and daylighting simulation using PHOTOPIA software, and experimental measurement under both solar simulator and real sky conditions. The results from both ray-tracing analysis and measurement have clearly shown the advantage of a solid dCPC over common prismatic structures for daylighting control, because it has a distinct acceptance 
1 angle for the incoming light. When it is orientated east-west, a solid dCPC rod with its front surface tilted

2 appropriately can give lower transmittance around the midday and larger transmittance in the morning or 3 afternoon for the sunny sky condition in the summer. This helps to reduce solar heat gain by shading off the 4 excessive solar radiation around the midday in the hot or warm seasons. In contrast, for the overcast sky 5 condition, the transmittance of a dCPC tends to be high and constant, and this is actually required when the 6 outdoor illuminance is low. A panel comprising an array of miniature dCPC can be used as a roof panel in 7 atrium or greenhouse buildings and the basis of the miniature dCPCs could be attached with PV cell. 8 Development of such panel for combined daylighting and PV application is undergoing and the outcome will 9 be reported soon. 
[1] Li DHW, Wong SL, Cheung KL. Energy performance regression models for office buildings with daylighting controls. Proceedings of the Institution of Mechanical Engineers, Part A: Journal of Power and Energy. 2008;222:557-68.

[2] Yao J, Zhu N. Evaluation of indoor thermal environmental, energy and daylighting performance of thermotropic windows. Building and Environment. 2012;49:283-90.

[3] Lim Y-W, Kandar MZ, Ahmad MH, Ossen DR, Abdullah AM. Building façade design for daylighting quality in typical government office building. Building and Environment. 2012;57:194-204.

[4] Freewan AA. Optimising the performance of innovative daylighting systems by integrating with ceiling geometries : field experiments and computer simulations. PhD Thesis: University of Nottingham; 2007.

[5] Claros S-T, Soler A. Indoor daylight climate-influence of light shelf and model reflectance on light shelf performance in Madrid for hours with unit sunshine fraction. Building and Environment. 2002;37:587-98.

[6] Shin JY, Yun GY, Kim JT. Evaluation of Daylighting Effectiveness and Energy Saving Potentials of Light-Pipe Systems in Buildings. Indoor and Built Environment. 2012;21:129-36.

[7] Ochoa CE, Capeluto IG. Evaluating visual comfort and performance of three natural lighting systems for deep office buildings in highly luminous climates. Building and Environment. 2006;41:1128-35.

[8] Kim JT, Kim G. Overview and new developments in optical daylighting systems for building a healthy indoor environment. Building and Environment. 2010;45:256-69.

[9] Han H, Tai Kim J. Application of high-density daylight for indoor illumination. Energy. 2010;35:2654-66.

[10] Littlefair PJ. Daylight in Atrium Buildings: Building Research Establishment (BRE); 1998.

[11] James PAB, Jentsch MF, Bahaj AS. Quantifying the added value of BiPV as a shading solution in atria. Solar Energy. 2009;83:220-31.

[12] Mayhoub MS, Carter DJ. The costs and benefits of using daylight guidance to light office buildings. Building and Environment. 2011;46:698-710.

[13] Christoffers D. Seasonal shading of vertical south-facades with prismatic panes. Solar Energy. 1996;57:339-43.

[14] Welford WT, Winston R. The optics of nonimaging concentrators: light and solar energy: Academic Press; 1978.

[15] Welford WT, Winston R. High collection nonimaging optics: Academic Press; 1989.

[16] Yuehong S, Gang P, Saffa BR, Hulin H. A Novel Lens-Walled Compound Parabolic Concentrator for Photovoltaic Applications. Journal of Solar Energy Engineering. 2012;134.

[17] Goodman NB, Ignatius R, Wharton L, Winston R. Solid-Dielectric Compound Parabolic Concentrators: On Their Use With Photovoltaic Devices. Applied Optics. 1976;15:2434-6.

[18] Guiqiang L, Gang P, Yuehong S, Xi Z, Jie J. Preliminary study based on building-integrated compound parabolic concentrators (CPC) PV/thermal technology. Energy Procedia. 2012;14:343-50.

[19] Mallick TK, Eames PC, Hyde TJ, Norton B. The design and experimental characterisation of an asymmetric compound parabolic photovoltaic concentrator for building façade integration in the UK. Solar Energy. 2004;77:319-27.

[20] Walze G, Nitz P, Ell J, Georg A, Gombert A, Hossfeld W. Combination of microstructures and optically functional coatings for solar control glazing. Solar Energy Materials and Solar Cells. 2005;89:233-48.

[21] Xue X, Zheng H, Su Y, Kang H. Study of a novel sunlight concentrating and optical fibre guiding system. Solar Energy. 2011;85:1364-70. 
1 [23] Oommen R, Jayaraman S. Development and performance analysis of compound parabolic solar

2 concentrators with reduced gap losses — 'V' groove reflector. Renewable Energy. 2002;27:259-75.

3 [24] Wittkopf SK. Daylight performance of anidolic ceiling under different sky conditions. Solar Energy. 4 2007;81:151-61.

5 [25] PHOTOPIA User Guide. [http://www.ltioptics.com/Photopia/overview.html], 2013

6 [26] SpringerReference. Fresnel Reflection Loss.

7 [http://www.springerreference.com/docs/html/chapterdbid/15129.html] , 2013. 


\section{Caption of Figures:}

Figure 1: three representative ray paths within dCPC 4

Figure 2: Truncation of CPC 4

Figure 3: Cross-sectional view of the dCPC and prismatic elements 5

Figure 4: Layout of dCPC rod in 3D space. 6

Figure 5: Picture of sample dCPC rod. Left: non-coated dCPC rod; Right: base-coated dCPC 6 $\operatorname{rod}$

Figure 6: Configuration (left) and 3D view (right) of photometric integrating box

Figure 7: the effect of covering board thickness on the light penetration under different incidence angles

Figure 8: conversion factor for the integrating box

Figure 9: integrating box under real sky for transmittance measurement $\quad 8$

Figure 10: Ray tracing result for $0^{\circ}$ incidence angle 9

Figure 11: Ray tracing result for $0^{\circ}$ incidence angle

Figure 12: Ray tracing result for $0^{\circ}$ incidence angle 9

Figure 13: simulated transmittance of the four prismatic structures under different incidence 9 angles

Figure 14: transmittance measurement under solar simulator and its comparison with simulated results

Figure 15: transmittance simulation of the four prismatic structures on sunny summer and winter solstices (Nottingham, south-facing, tilted $30^{\circ}$ )

Figure 16: seasonal variance of transmittance for four prismatic structures under sunny sky (Nottingham, south-facing, tilted $30^{\circ}$ )

Figure 17: seasonal variance of transmitted daylighting illuminance level for four prismatic structures under sunny sky (Nottingham, south-facing, tilted $30^{\circ}$ )

Figure 18: seasonal variance of transmittance for four prismatic structures under overcast sky (Nottingham, south-facing, tilted $30^{\circ}$ )

Figure 19: seasonal variance of daylighting illuminance level for four prismatic structures under overcast sky (Nottingham, south-facing, tilted $30^{\circ}$ )

Figure 20: Measured ttransmittance of three optical rodsdCPC rod with and without base- 
coated and external illuminance, 9th July 2013 (sunny)

Figure 21: Measured transmittance of three optical rodsdCPC rod with and without basecoated and external illuminance, 10th July 2013 (overcast)

1

2

3

4

5

6

7

8

9

10

11

12

13

14

15

16

17

18

19

20

21

22

23

24

25

26

27

28

29

30

31

32

33

34 


\section{Caption of Table:}

Table 1: Summary of three representative ray paths in $\mathrm{dCPC}$ and suitable their buildingintegrated applications 
Table 1: Summary of three representative ray paths in $\mathrm{ACPC}$ and suitable applications

\begin{tabular}{|c|c|c|c|c|}
\hline Ray Number & $\begin{array}{l}\text { Incidence Angle } \\
\text { Compare to the } \\
\text { Outer Acceptance } \\
\text { Angle of dCPC }\end{array}$ & $\begin{array}{l}\text { Situation in Real Sky } \\
\text { Condition }\end{array}$ & Ray Destination & $\begin{array}{l}\text { Building-integrated } \\
\text { Application }\end{array}$ \\
\hline $\mathbf{a}$ & Larger & $\begin{array}{l}\text { Most diffused skylight } \\
\text { and some direct } \\
\text { sunlight at low } \\
\text { elevation angle }\end{array}$ & $\begin{array}{l}\text { The ray will escape } \\
\text { from the lower side } \\
\text { of lateral wall of a } \\
\text { dCPC }\end{array}$ & $\begin{array}{l}\text { Daylighting: the } \\
\text { diffused skylight and } \\
\text { low altitude sunlight } \\
\text { with low solar } \\
\text { radiation is preferred } \\
\text { by building occupants }\end{array}$ \\
\hline b & $\begin{array}{l}\text { Equal (Cut-off } \\
\text { angle) }\end{array}$ & $\begin{array}{l}\text { Edge condition } \\
\text { between } \mathbf{a} \text { and } \mathbf{b}\end{array}$ & $\begin{array}{l}\text { The ray reach the } \\
\text { edge between } \\
\text { lateral wall and exit } \\
\text { aperture of dCPC } \\
\text { rod }\end{array}$ & N/A \\
\hline c & Smaller & $\begin{array}{l}\text { Most direct sunlight at } \\
\text { high elevation angle }\end{array}$ & $\begin{array}{l}\text { The ray will be } \\
\text { concentrated to the } \\
\text { base of a dCPC } \\
\text { (e.g., attached with } \\
\text { PV cells) }\end{array}$ & $\begin{array}{l}\text { Concentrating PV } \\
\text { system: the increased } \\
\text { light intensity } \\
\text { improves the } \\
\text { efficiency of PV cell }\end{array}$ \\
\hline
\end{tabular}


Figure 1

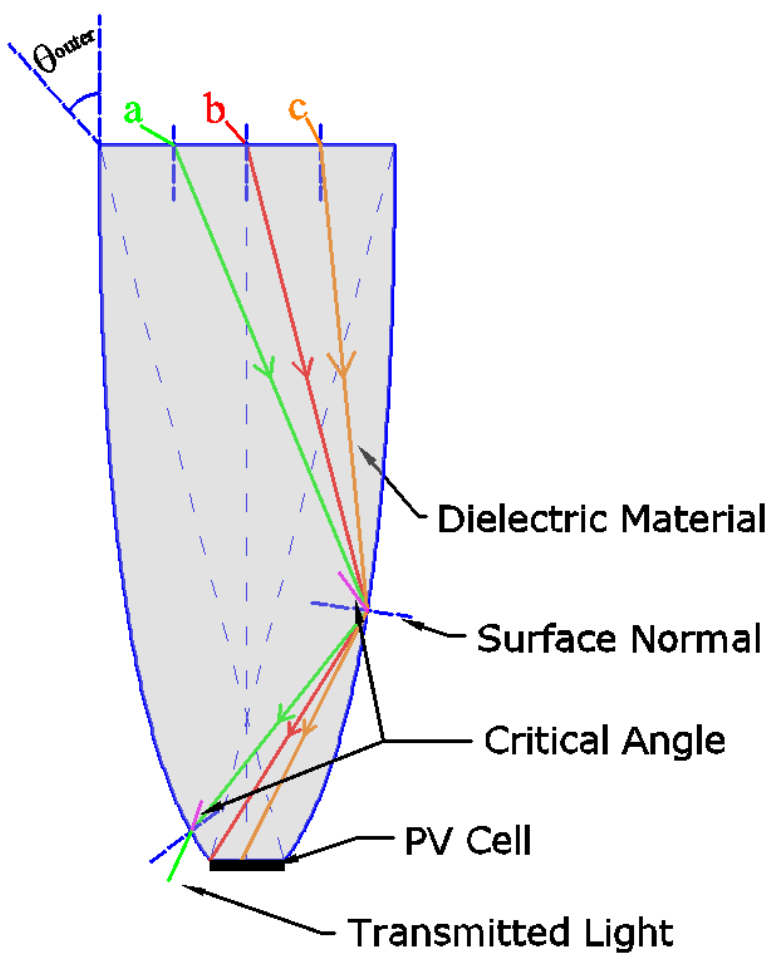

Figure 1: three representative ray paths within $d C P C$ 
Figure 1

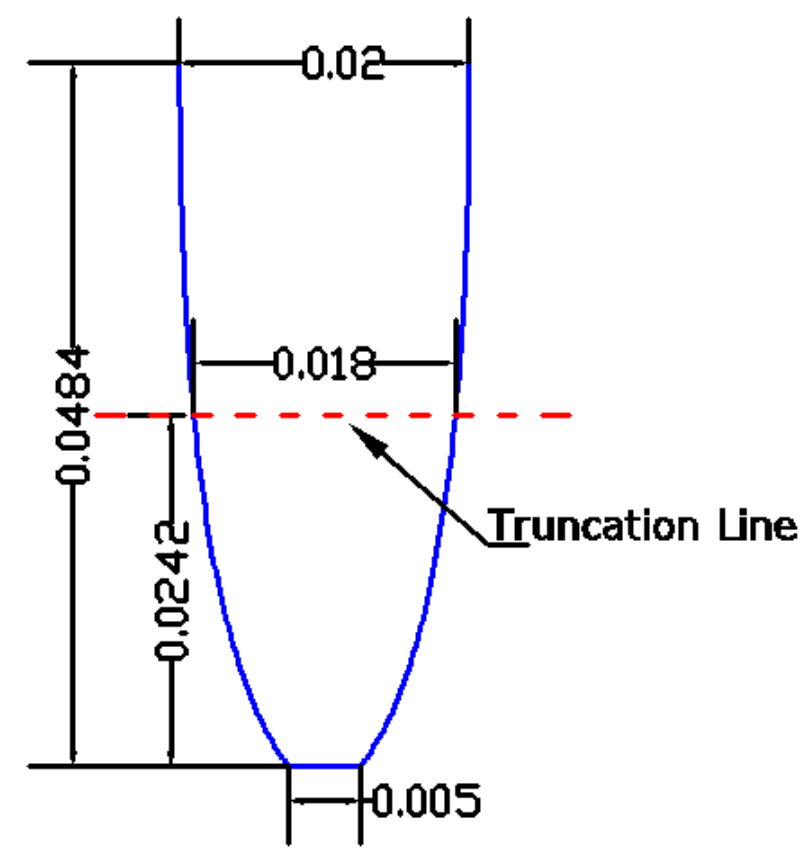

Figure 2: Truncation of CPC 
Figure 3

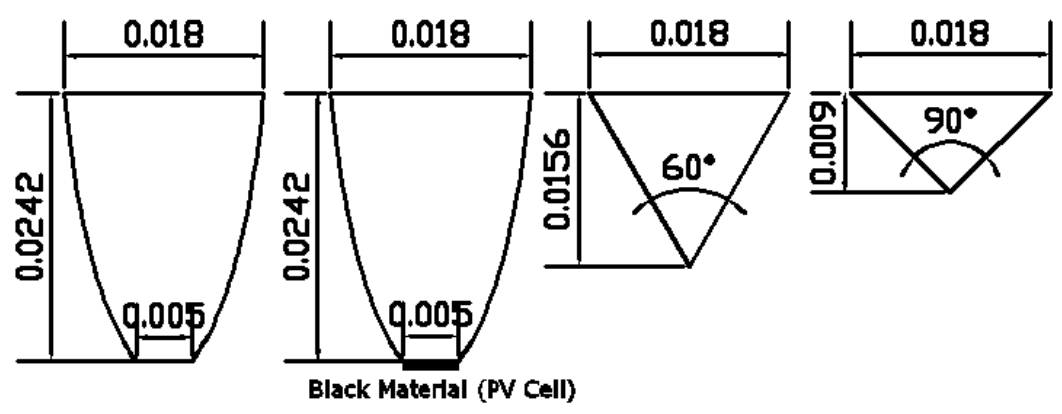

Figure 3: Cross-sectional view of the CPC and prismatic elements 
Figure 4

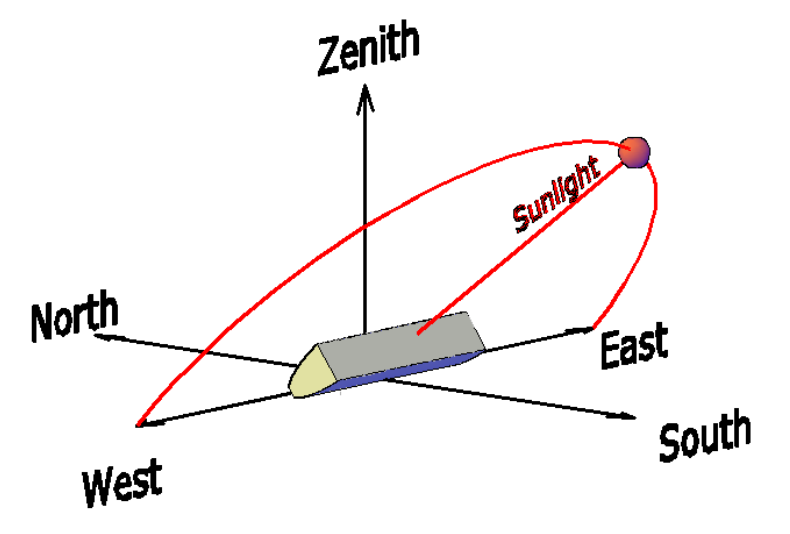

Figure 4: Layout of dCPC rod in 3D space.

West

South

(1)

rong

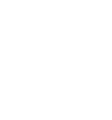

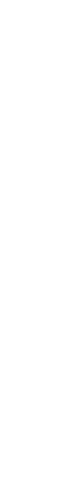

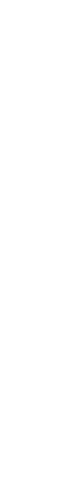

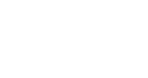

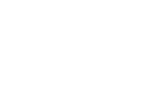
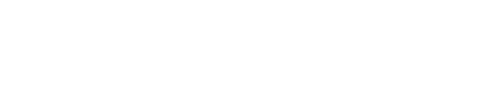

(

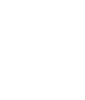

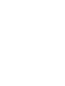

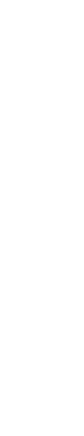

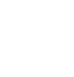


Figure 6
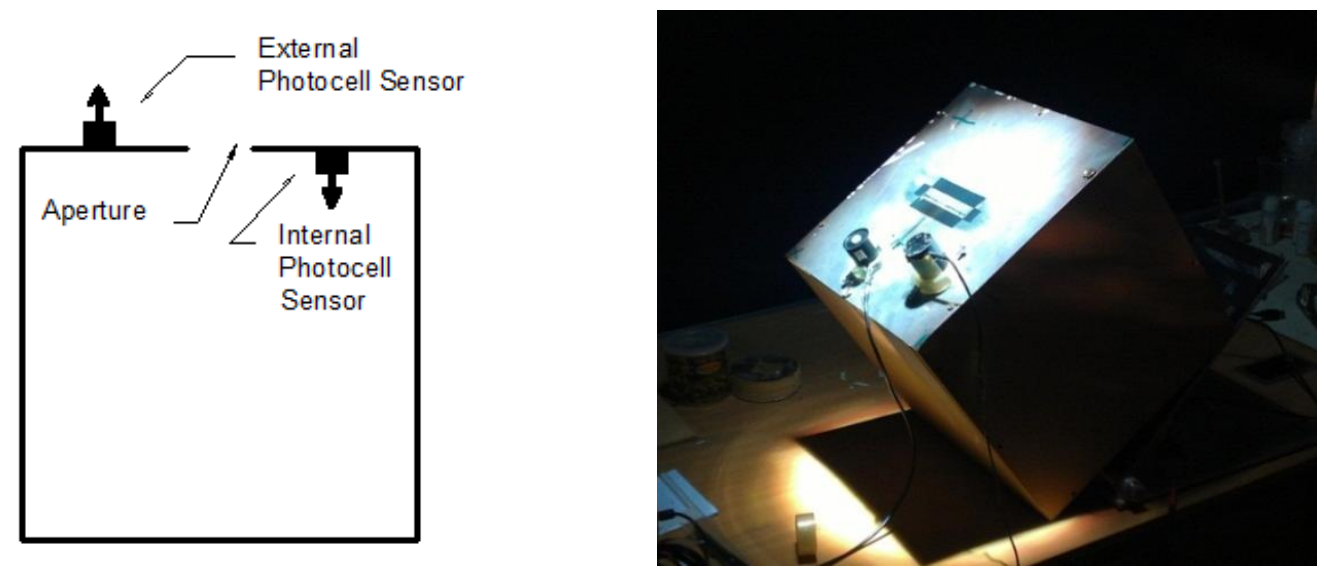

Figure 6: Configuration (left) and 3D view (right) of photometric integrating box 


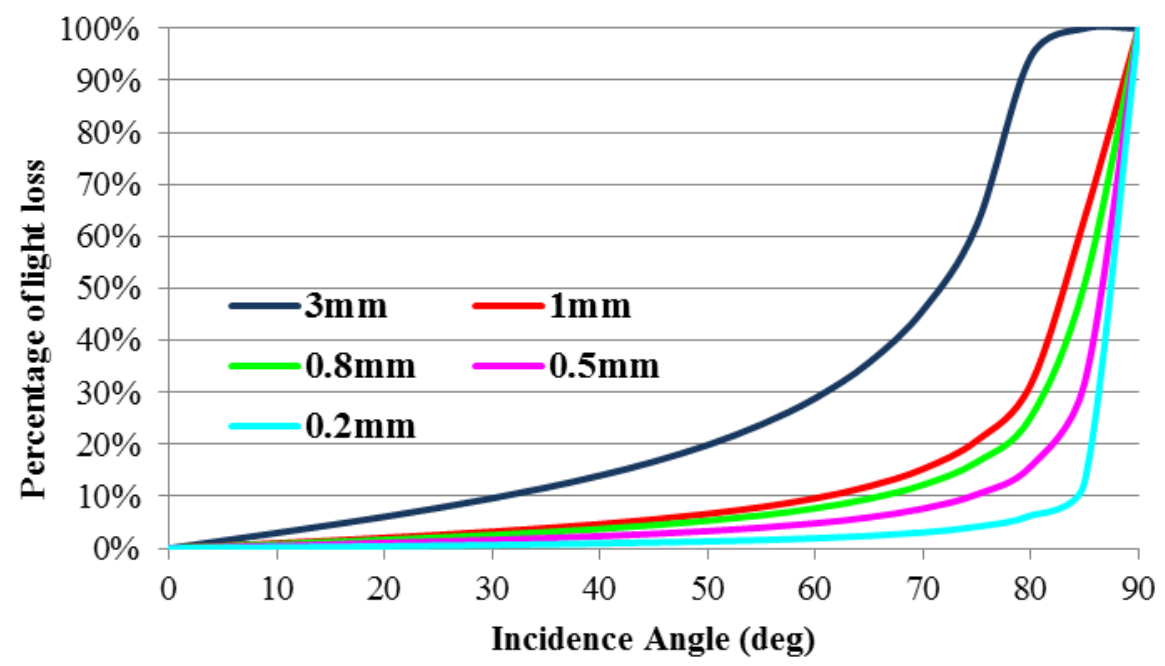

Figure 7: the effect of covering board thickness on the light penetration under different incidence angles. 
Figure 8

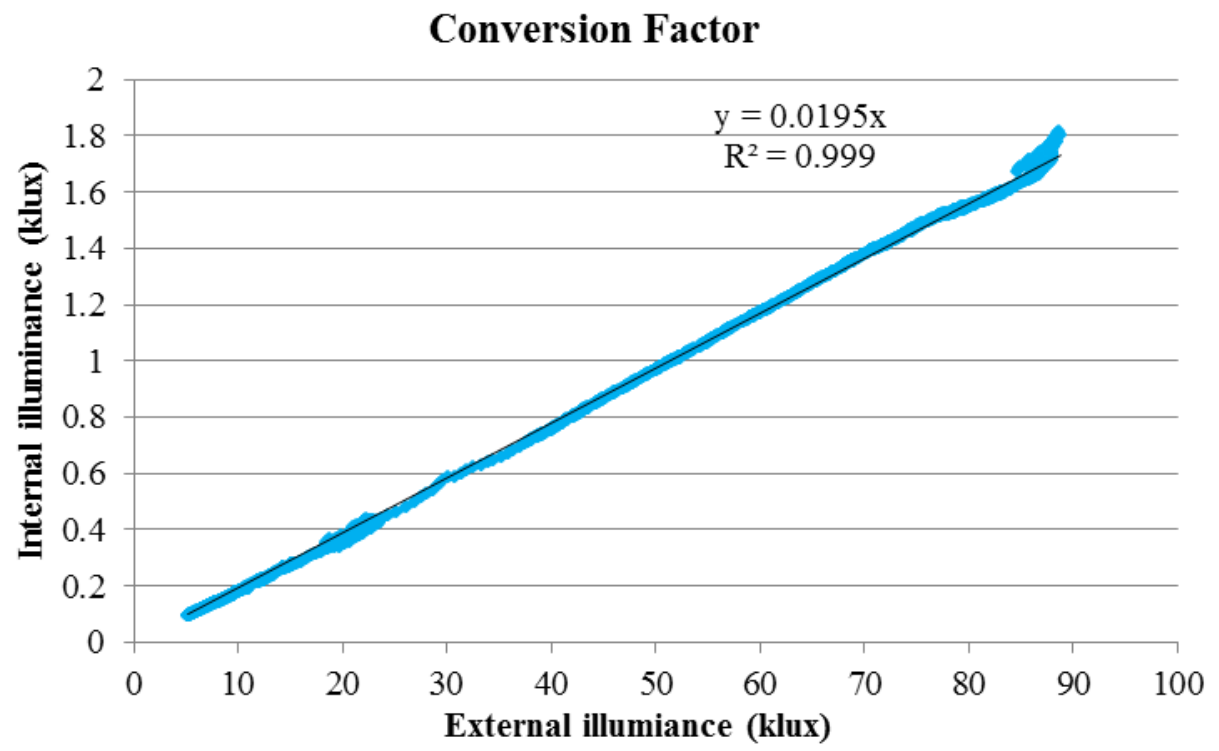

Figure 8: conversion factor for the integrating box 

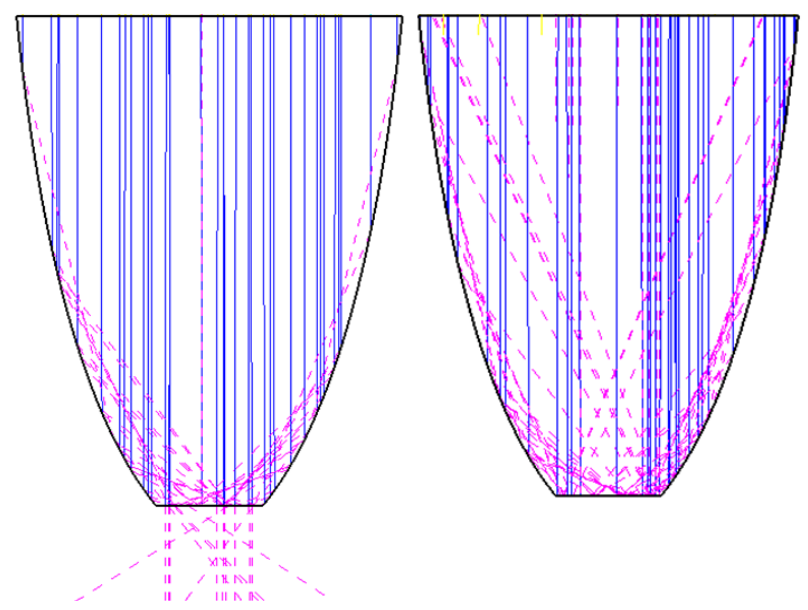

$\begin{array}{ll}\text { (a) non-coated dCPC } & \text { (b) base-coated dCPC }\end{array}$

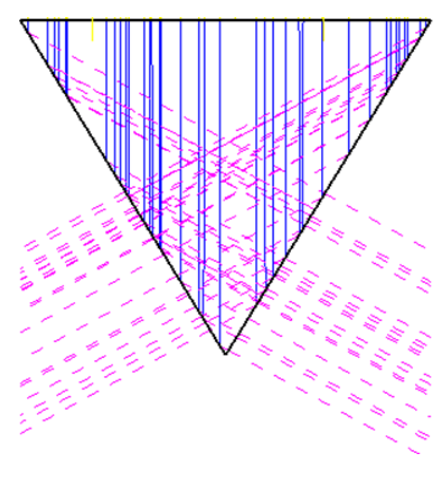

(c) equilateral triangle

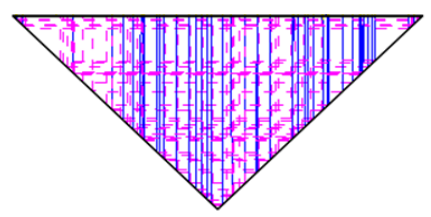

(d) isosceles right triangle

Figure 10: Ray tracing result for $0^{\circ}$ incidence angle 


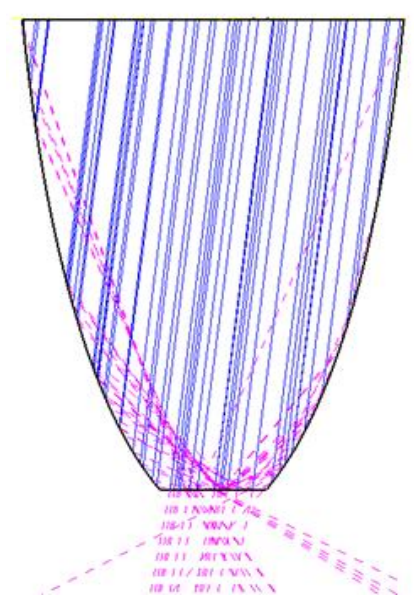

(a) non-coated dCPC (b) base-coated dCPC

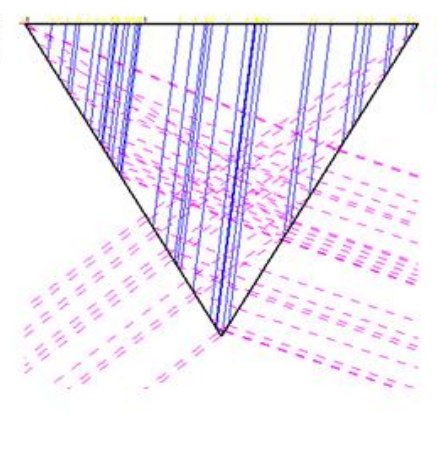

(c) equilateral triangle

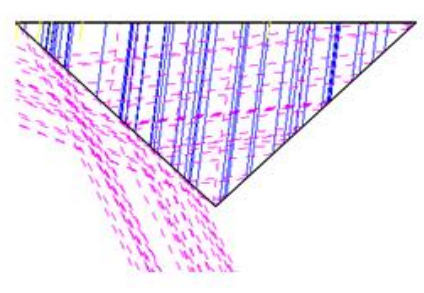

(d) isosceles right triangle

Figure 11: Ray tracing result for $10^{\circ}$ incidence angle 


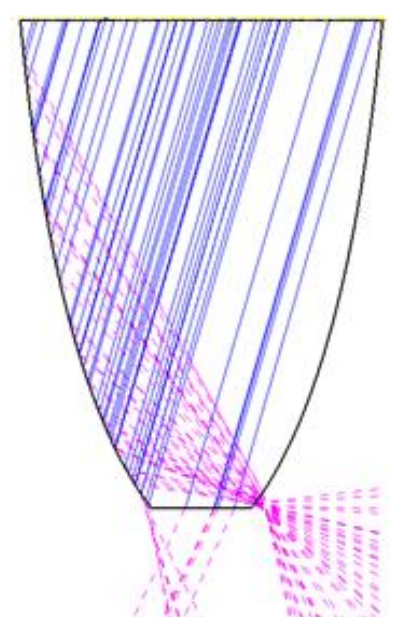

(a) non-coated dCPC

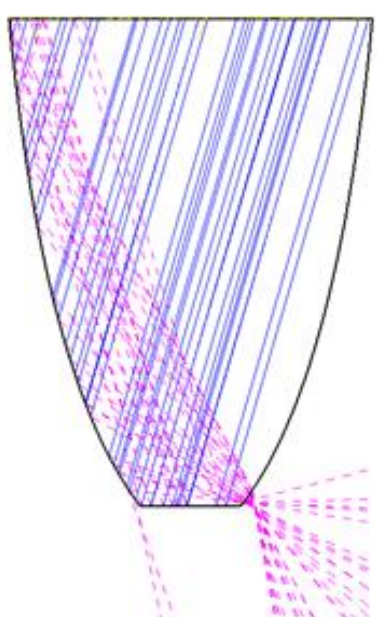

(b) base-coated dCPC

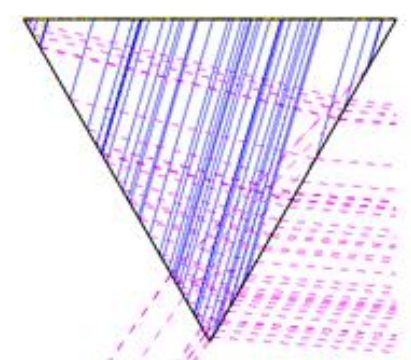

(c) equilateral triangle

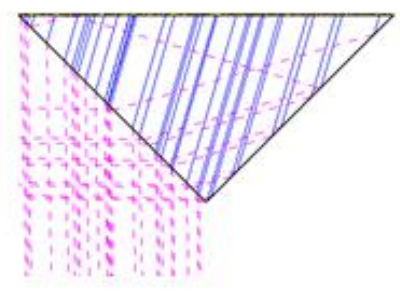

(d) isosceles right triangle

Figure 12: Ray tracing result for $25^{\circ}$ incidence angle 


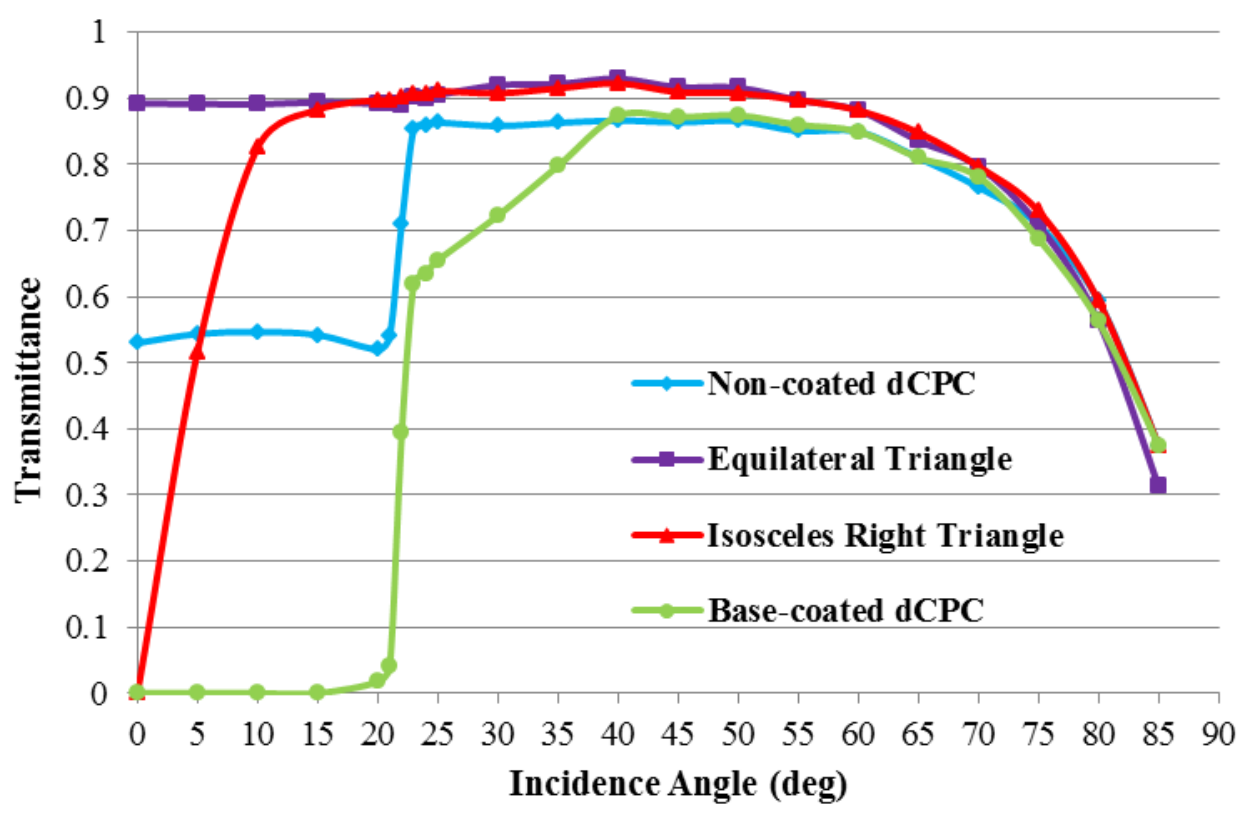

Figure 13: simulated transmittance of the four prismatic structures under different incidence angles 


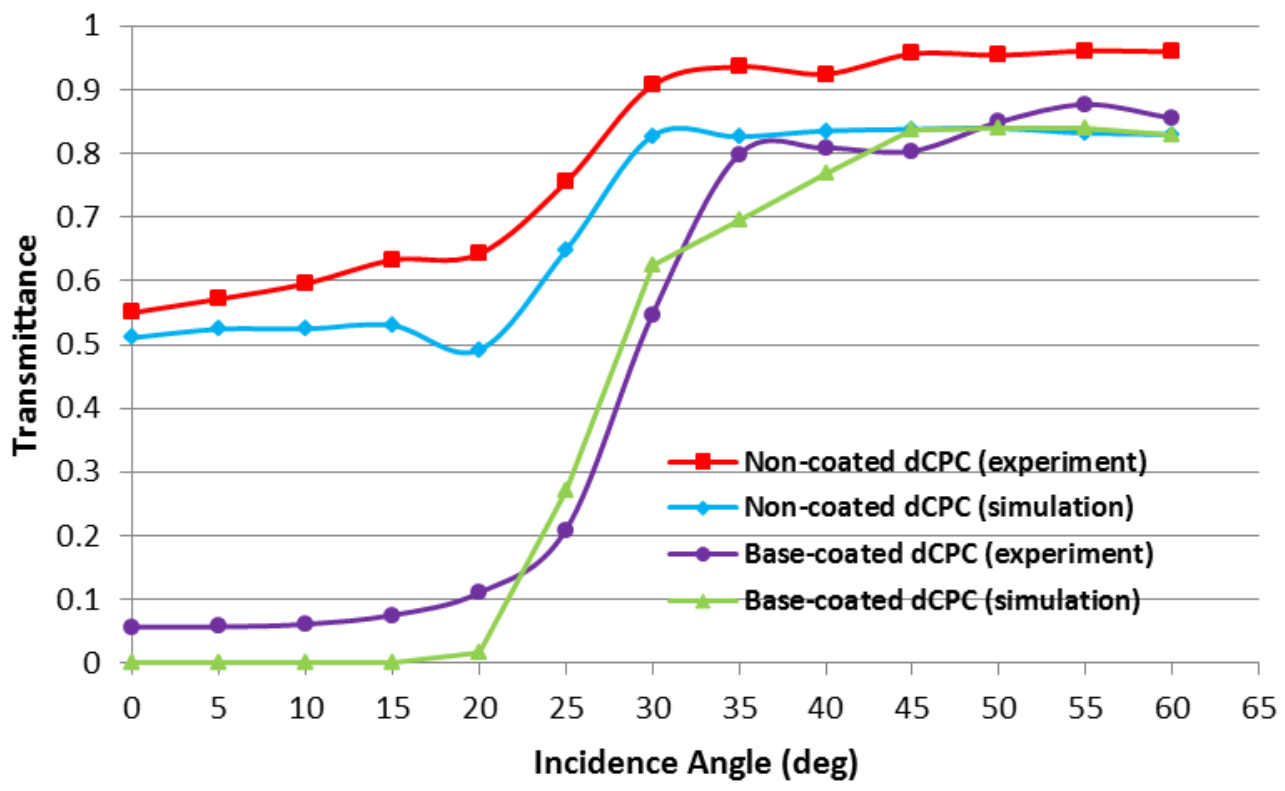

Figure 14: transmittance measurement under solar simulator and its comparison with simulated results 

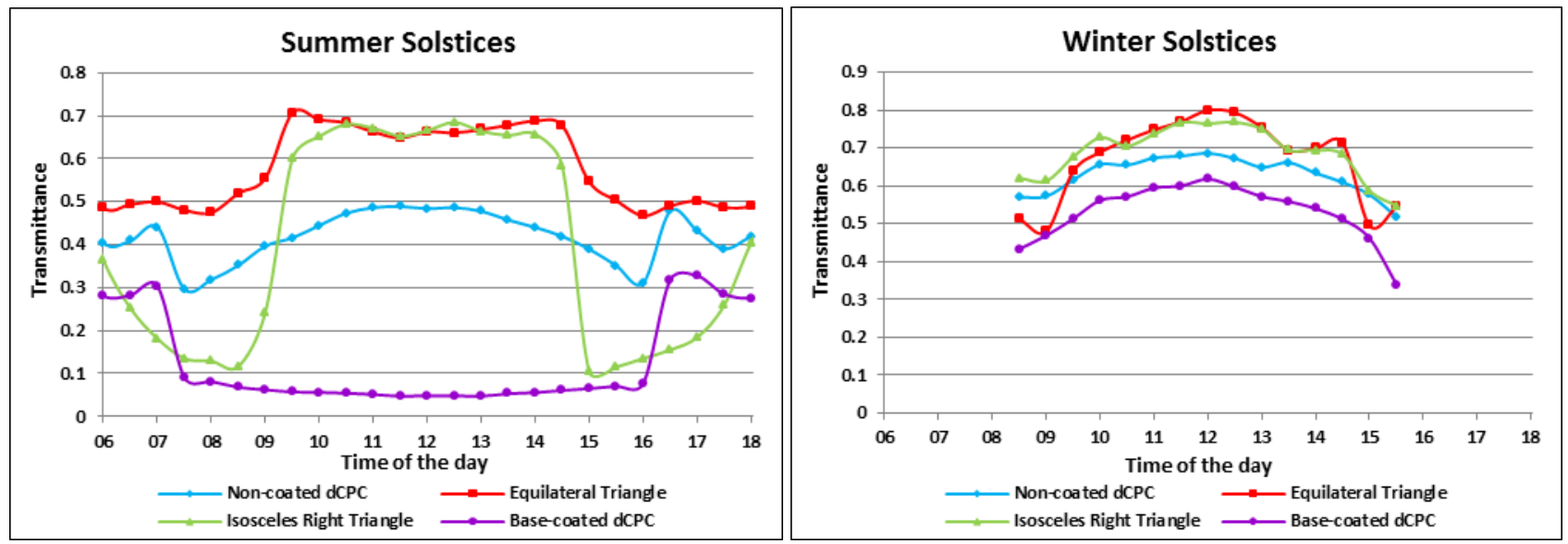

Figure 15: transmittance simulation of the four prismatic structures on sunny summer and winter solstices (Nottingham, south-facing, tilted $30^{\circ}$ ) 

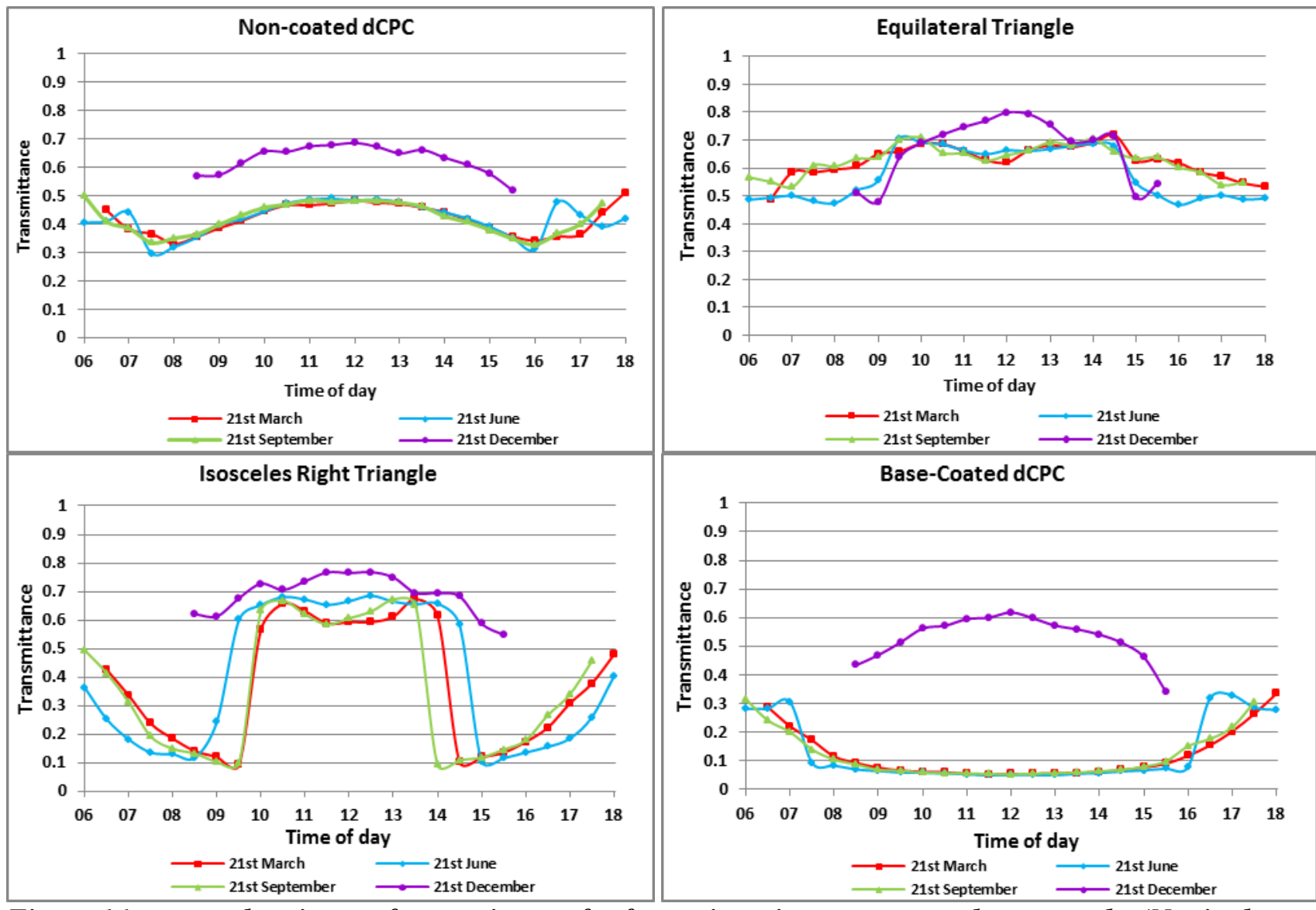

Figure 16: seasonal variance of transmittance for four prismatic structures under sunny sky (Nottingham, south-facing, tilted $30^{\circ}$ ) 

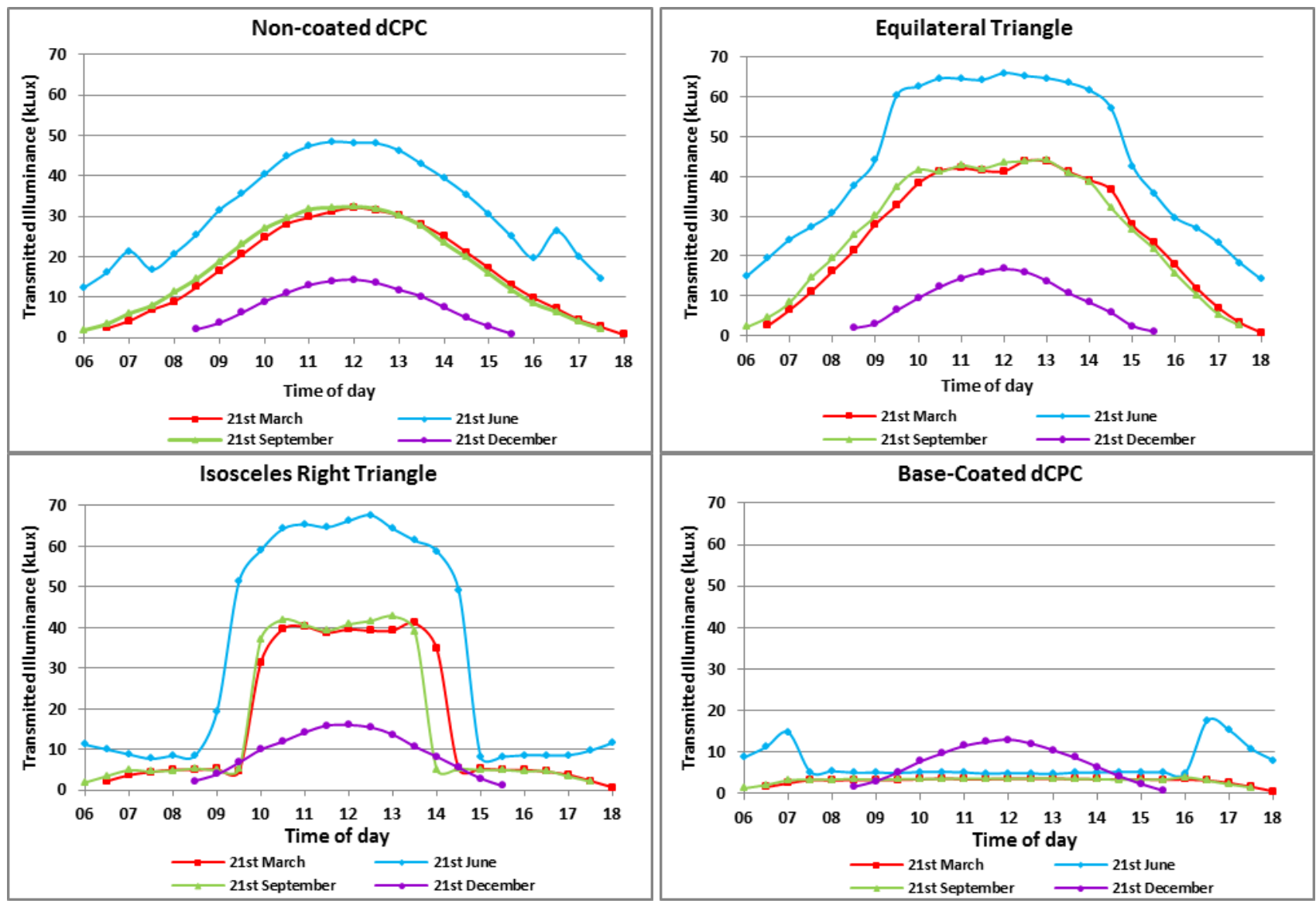

Figure 17: seasonal variance of transmitted daylighting illuminance level for four prismatic structures under sunny sky (Nottingham, south-facing, tilted 30 ${ }^{\circ}$ ) 

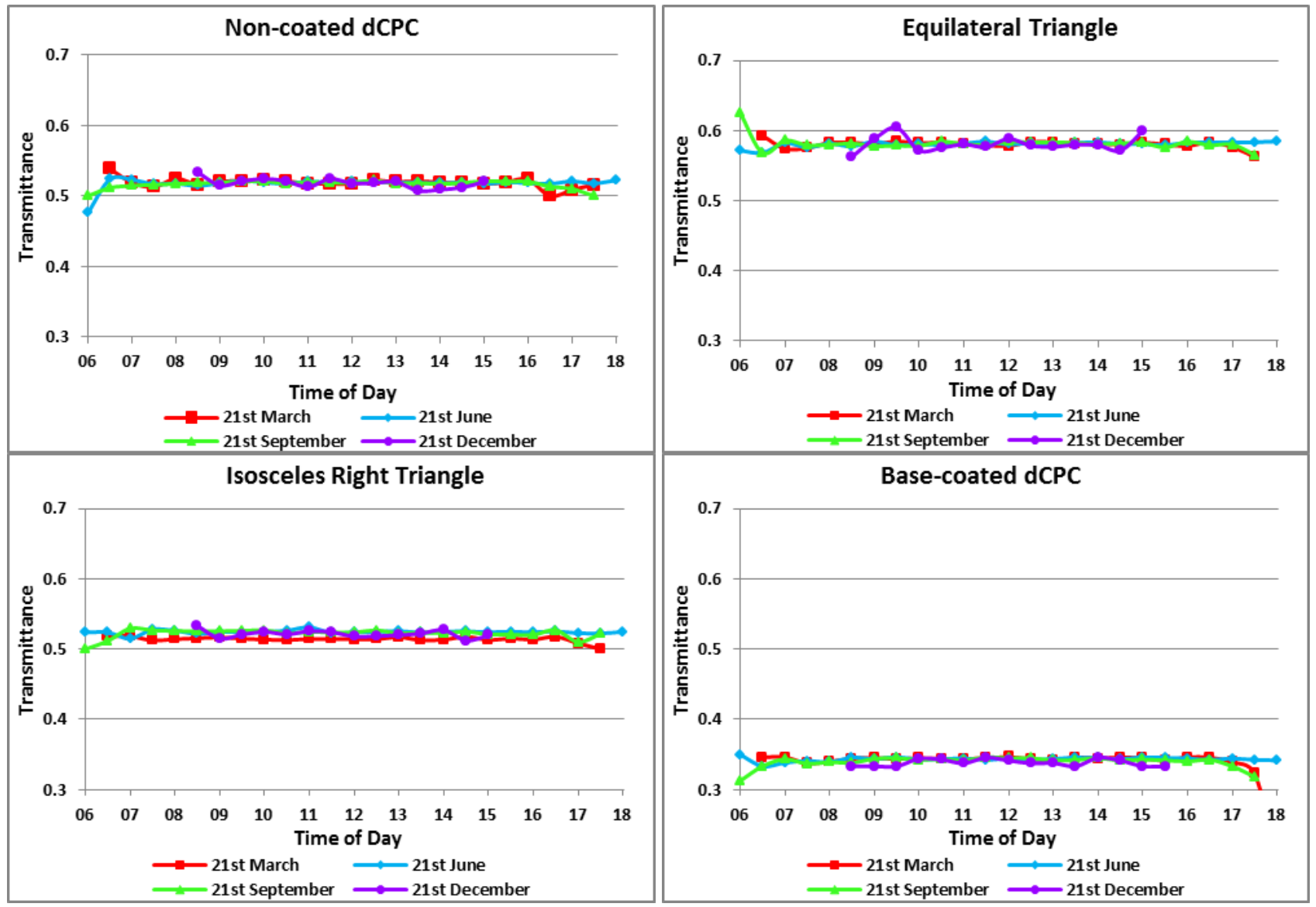

Figure 18: seasonal variance of transmittance for four prismatic structures under overcast sky (Nottingham, south-facing, tilted $30^{\circ}$ ) 

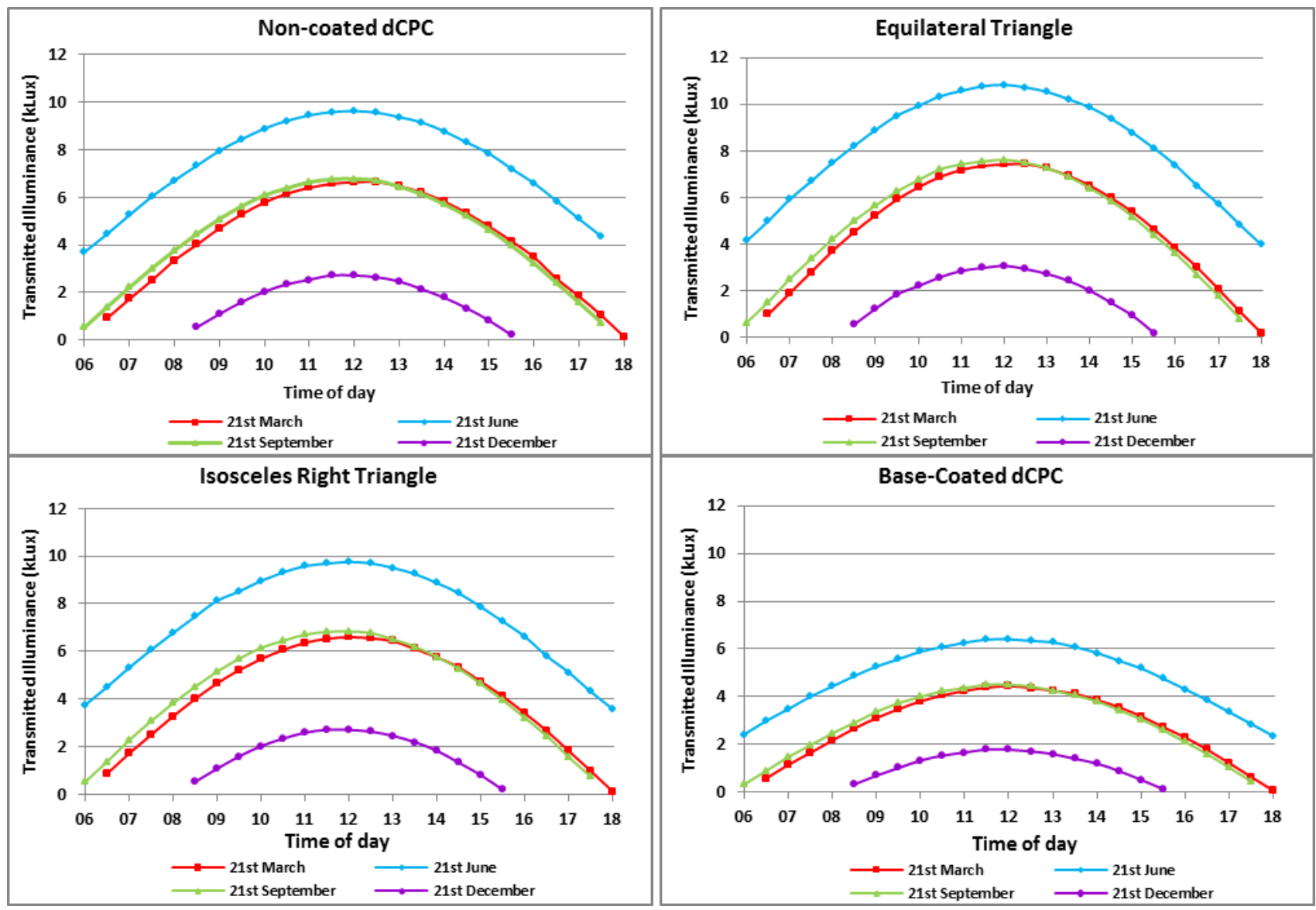

Figure 19: seasonal variance of daylighting illuminance level for four prismatic structures under overcast sky (Nottingham, south-facing, tilted $30^{\circ}$ ) 


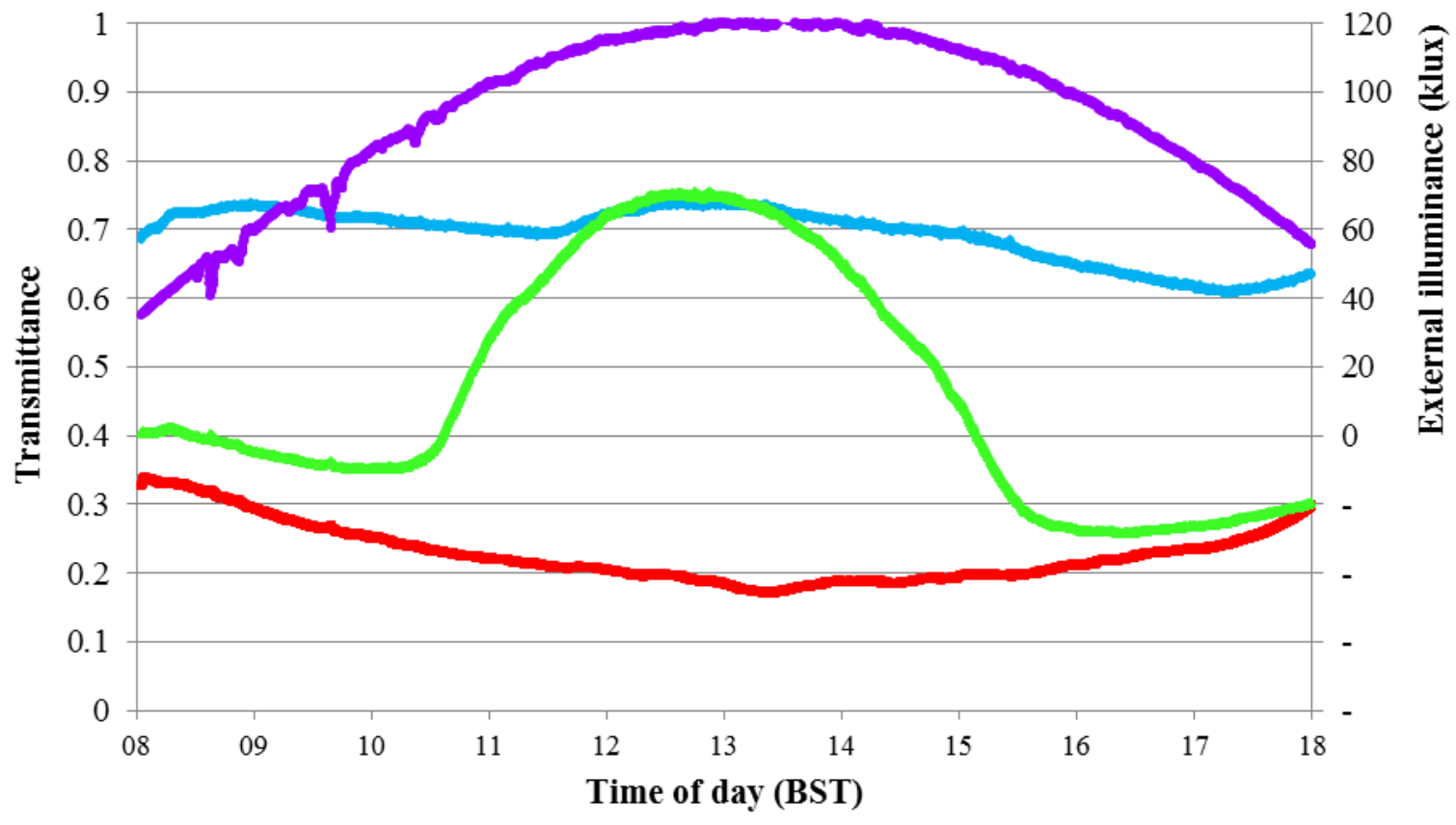

$\longrightarrow$ Non-coated dCPC $\longrightarrow$ Base coated dCPC $\longrightarrow$ Isosceles right triangle $\longrightarrow$ External illumiance

Figure 20: Measured transmittance of three optical rods and external illuminance, $9^{\text {th }}$ July 2013 (sunny) 


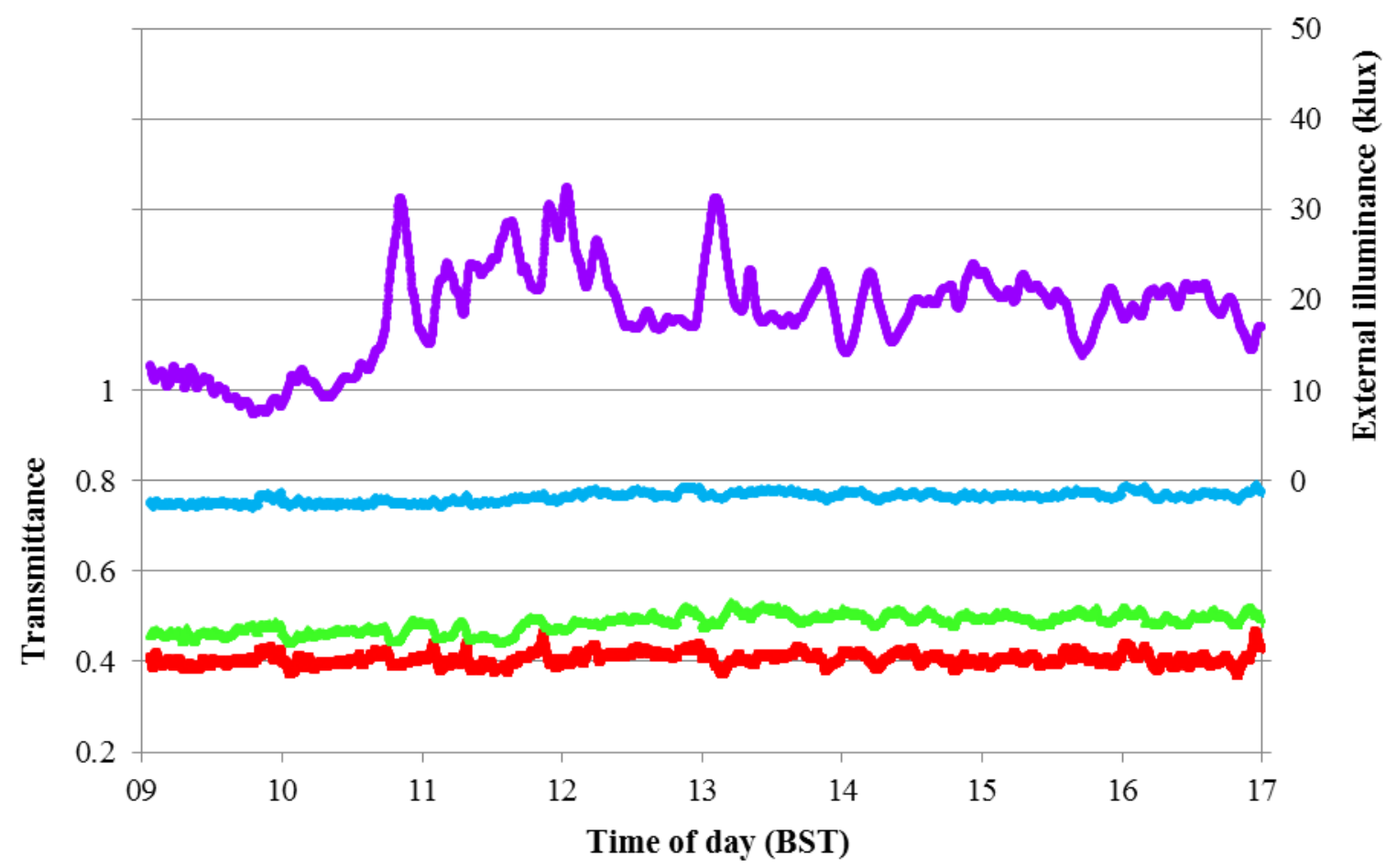

$\longrightarrow$ Non-coated dCPC $\longrightarrow$ Base-coated dCPC $\longrightarrow$ Isosceles right triangle $\longrightarrow$ External illumin ance

Figure 21: Measured transmittance of three optical rods and external illuminance, $10^{\text {th }}$ July 2013 (overcast) 